\title{
Cryo-quenched Fe-Ni-Cr alloy single crystals: A new decorative steel
}

\author{
L. A. Boatner ${ }^{1}$, J. A. Kolopus ${ }^{1}$, Nicolay V. Lavrik ${ }^{2}$, and P. Sudharshan Phani ${ }^{3}$
}

${ }^{1}$ Materials Science and Technology Division, ${ }^{2}$ Center for Nanophase Materials Sciences, Oak Ridge National Laboratory, Oak Ridge, TN 37831, ${ }^{3}$ Nanomechanics, Inc., Oak Ridge, TN 37831

*Corresponding author. Oak Ridge National Laboratory, 1 Bethel Valley Road, Oak Ridge, TN 37831, USA

E-mail address: boatnerla@ornl.gov (L. A. Boatner)

\begin{abstract}
A decorative steel is described that is formed by a process that is unlike that of the fabrication methods utilized in making the original Damascus steels over 2,000 years ago. The decorative aspect of the steel arises from a three-dimensional surface pattern that results from cryogenically quenching polished austenitic alloy single crystals into the martensitic phase that is present below $190 \mathrm{~K}$. No forging operations are involved - the mechanism is entirely based on the metallurgical phase properties of the ternary alloy. The symmetry of the decorative pattern is determined and controlled by the crystallographic orientation and symmetry of the $70 \% \mathrm{Fe}, 15 \% \mathrm{Ni}, 15 \% \mathrm{Cr}$ alloy single crystals. In addition to using "cuts" made along principal crystallographic surface directions, an effectively infinite number of other random-orientation "cuts" can be utilized to produce decorative patterns where each pattern is unique after the austenitic-to-martensitic phase transformation.
\end{abstract}




\subsection{Introduction}

The origin and fabrication processes of the first decorative steel (commonly called "Damascus steel") are enduring subjects of controversy that remain shrouded in uncertainty. In fact, according to some reports, the origin of Damascus steels can be traced back more than two thousand years - since a sword incorporating this material is reported to having been given to Alexander the Great as early as $323 \mathrm{BC}$ [1]. One process for producing this steel was based on the use of a very high-carbon-content composition known as wootz steel [2,3] whose production originated in India. Wootz steel was subsequently shipped to Damascus and the Middle East where it was used to manufacture swords and other edged weapons with unusual surface markings that combined exceptional beauty with legendary metallurgical quality, since the steel also exhibited the attributes of extreme hardness and edge retention in combination with mechanical toughness. In terms of their decorative properties, Damascus steels exhibit inherent and characteristic attractive structural patterns that vary in their design. Unfortunately, sometime around the middle of the $18^{\text {th }}$ century, the original Damascus steel and associated sword-making process was lost. A number of prior research efforts directed toward the reproduction of the original high-carbon-content Damascus steel process have subsequently been carried out. Particularly noteworthy is the extensive and careful work of J. D. Verhoeven and A. H. Pendray and their colleagues [4-8] as well as the work of Wadsworth and Sherby [9], N. Kobasko [10], and E. M. Taleff et al [11]. It should be noted, however, that these more recent attempts to produce an analog of the 
original Damascus steel have been, and potentially remain, a subject of some controversy and dispute. [12-14] The process for forming Damascus as well as different variations of so-called "pattern-welded steels" [1] has generally and historically been a closely guarded trade secret - so it is possible that there may actually be more than one route that was or could be used to produce such materials.

The history of the use of metals in swords and other edged weapons in the period between 7,000 B.C. and the 1800's has been reviewed in several articles by combinations of the authors: John D. Verhoeven and A. H. Pendray and their colleagues [4-8] as well as Wadsworth, Sherby, and Lesuer,[15-20] These cumulative reviews cover metals ranging from pure copper to more modern steels as well as Damascus Steels and layered/composite steels. These reviews also point out that a second group of materials exists that is known as "welded Damascus steels" or "pattern welded steels." While these steels exhibit a decorative patterning, they differ significantly from the original Damascus steel in terms of their fabrication methods, microstructure, composition, and decorative characteristics. The "pattern welded" steels are formed by forging (i.e., mechanically welding at elevated temperature) alternating components of iron and steel together followed by repeated folding and re-forging of the billet to produce multiple layers (sometimes hundreds of layers) of the component materials. The resulting decorative patterns arise from the contrasting colors of the various "multiple" layers of the forged composite material. Recently this "pattern welding" process has been widely applied to the formation of modern custom and commercial knives and cutlery, and current blacksmithing techniques, including traditional hand forging and machine-hammer forging, are used to produce "manufactured" complex and artistic patterns. 
Here we describe a new decorative steel that is markedly different from either the original Damascus steel or "pattern-welded" steels. Specifically, the decorative steel described here is, in fact, different in terms of: the metallurgical production and fabrication process, the physical mechanism responsible for producing the decorative pattern, the symmetry properties of the decorative patterns, and the optical effects that produce the decorative features. The step-by-step process for forming the subject decorative steel is described here in order to hopefully avoid future controversy regarding its production - and also with the goal of avoiding the loss of the process (as in the case of Damascus steel) for the next several hundreds of years.

\subsection{Material and methods}

The decorative steel described here is produced by first growing single crystals of a $70 \mathrm{wt} \% \mathrm{Fe}-15 \mathrm{wt} \% \mathrm{Ni}-15 \% \mathrm{wt} \% \mathrm{Cr}$ or related austenitic alloy, cutting slices of the material (usually but not necessarily along oriented crystallographic directions), highly polishing the sample surfaces, and then cryogenically quenching the material through the austenitic to martensitic phase transition that occurs at $190 \mathrm{~K}$ for the specific $70 \mathrm{wt} \% \mathrm{Fe}-15 \mathrm{wt} \% \mathrm{Ni}$ $15 \% \mathrm{wt} \% \mathrm{Cr}$ composition used here. This quenching process is the final step in forming the patterned steel for use in a decorative item of any kind, (e.g., knife blades or bolsters, jewelry, etc.). The decorative steel component must be shaped only by the "metal removal" process and then highly polished before this last step is undertaken.

Hammering or forging is deleterious to the process of forming the decorative steel in that such steps will distort and alter the ordered single-crystal structure.

As noted above, the initial step in forming the new decorative steel is the growth 
of a single crystal of an austenitic alloy like $70 \mathrm{wt} \% \mathrm{Fe}-15 \mathrm{wt} \% \mathrm{Ni}-15 \% \mathrm{wt} \% \mathrm{Cr}$ - i.e., in general, an alloy that undergoes an austenitic-to-martensitic phase transition on cooling into the cryogenic temperature range. In the present example, the alloy crystals were grown by means of the Czochralski or "crystal pulling" technique [21]. An oriented single-crystal "seed" was utilized, and the melt from which the crystal was "pulled" was contained in a high-purity alumina crucible that was placed inside a graphite susceptor. Radio-frequency induction heating was employed, and the growth process was carried out using a Varian Multi-purpose crystal growth unit. A growth ambient consisting of purified argon at a pressure slightly in excess of one atmosphere was maintained in the growth chamber during the "crystal-pulling" and ensuing cool-down operations. Highpurity elemental components (e.g., 99.99 to $99.999 \%$ pure $\mathrm{Fe}, \mathrm{Ni}$, and $\mathrm{Cr}$.) were used to form the alloy, and these components were cleaned and chemically etched prior to being placed in the alumina crucible for subsequent alloying and crystal growth. In spite of these factors of initial purity and subsequent etching, a layer of oxide (i.e., slag) formed and floated on the surface of the alloy melt, and this surface layer resulted in the multiple nucleation of crystal grains and essentially prevented the Czochralski growth of the desired one single crystal. A physical method and associated growth system configuration were used to remove this undesirable layer of material prior to the "crystalpulling" step. In a commercial or mass-production setting, single crystals of this and similar alloys in this composition range could potentially be manufactured and mass produced using the Bridgman growth (i.e., directional solidification) technique that is currently applied to the production of high-performance single-crystal turbine blades. High-purity oriented single crystals like those described here were previously grown and 
used in a number of fundamental studies of solidification phenomena. Descriptions of the microstructural, physical, and morphological properties of melt or weld pools formed using single crystals of the present alloy can be found in the references. [22-25]

Laue back-reflection X-ray methods were used to orient the $70 \mathrm{wt} \% \mathrm{Fe}-15 \mathrm{wt} \% \mathrm{Ni}-$ $15 \% \mathrm{wt} \% \mathrm{Cr}$ austenitic alloy single crystals that were then cut using an electric-arc discharge machine to expose the desired crystal surfaces. Since the symmetry pattern of the decorative features is dependent on the crystallographic orientation of the exposed surfaces, these surface cuts can be chosen (depending on the original orientation of the as-grown crystal) perpendicular to either the (100), (110), or (111) directions of the facecentered-cubic (fcc) material - although non-principal crystallographic orientations can also be employed to produce decorative patterns with varying symmetries. After shaping of the item to be produced by the metal-removal method, the work piece with its crystallographically oriented surfaces is lapped and then given a final high polish ideally by using a colloidal silica suspension. In the final fabrication step, the material is transformed from the austenitic to the martensitic phase by immersion in liquid nitrogen followed by a return to room temperature. This austenitic-martensitic phase transition occurs at $190 \mathrm{~K}$. Multiple cryo-quenching cycles produced by cooling the material to 77 $\mathrm{K}$ followed by warming to room temperature were found to slightly enhance the magnitude of the desired surface relief pattern.

\subsection{Results and discussion}

Figure 1(a) shows an example of the decorative surface pattern formed on a (100) -oriented surface (note the $90^{\circ}$ angles) of the $70 \mathrm{wt} \% \mathrm{Fe}-15 \mathrm{wt} \% \mathrm{Ni}-15 \% \mathrm{wt} \% \mathrm{Cr}$ alloy used here. Optical profilometry was employed to determine the magnitude of the height of the 
surface features induced by cryogenic quenching of the ternary single-crystal alloy and resulting in the surface-relief optical properties that produce the decorative pattern shown in Fig. 1a. These profilometry results are shown in Fig. 1(b) in a three-dimensional plot obtained for the segment of the surface that is indicated in the optical photograph located on the left hand side of the 3-D color plot. The magnitude of the surface relief is indicated by the color scale-bar located on the right hand side of Fig. 1(b.). This surface relief spans a range of $\sim 110$ microns in this case - a value that is generally representative of the surface morphology of the overall decorative steel specimen.
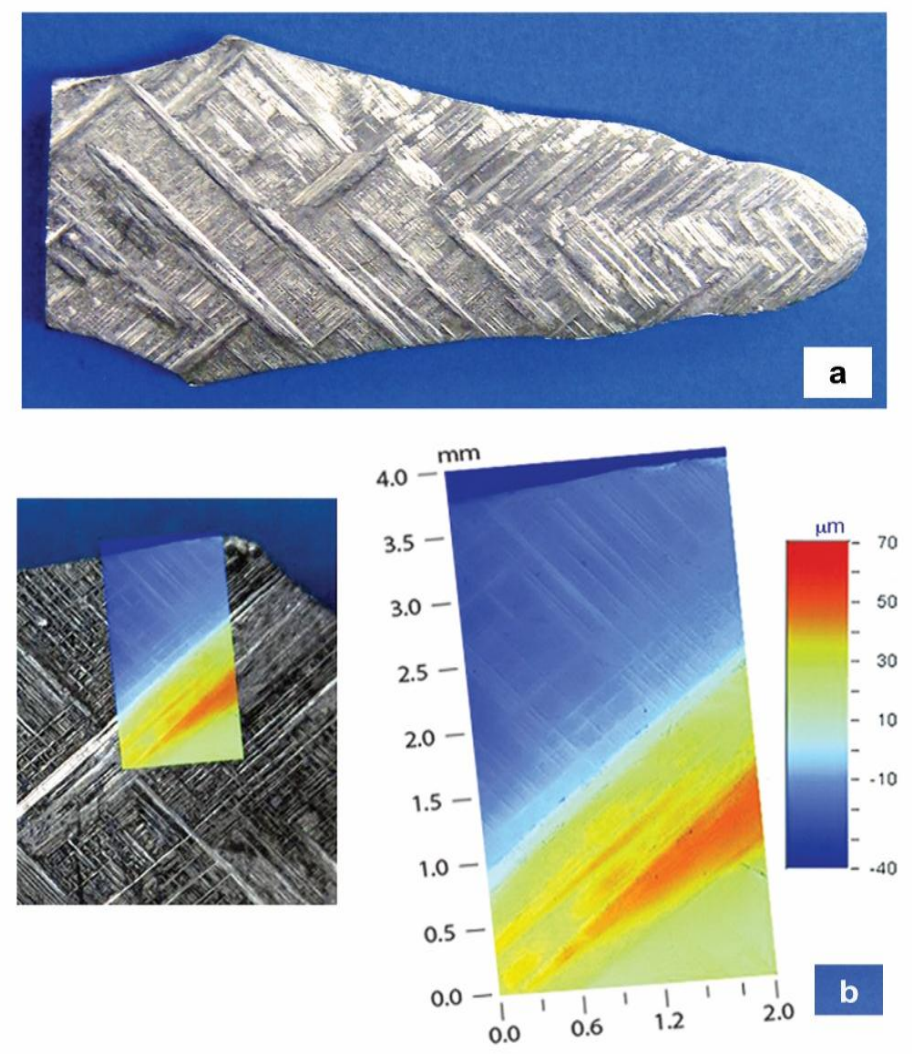

Fig. (1a). The decorative pattern formed on a (100)-oriented surface of the $70 \mathrm{wt} \% \mathrm{Fe}-15 \mathrm{wt} \% \mathrm{Ni}-15 \% \mathrm{wt} \% \mathrm{Cr}$ austenitic alloy single crystal after cryo-quenching to 77 $\mathrm{K}$ and then warming to room temperature. The sample is $\sim 6.0 \mathrm{~cm}$ in length. (1b). 
Overlay of an optical image with a 3-D profile map of the indicated $4 \times 2 \mathrm{~mm}$ fragment area. The magnitude of the surface relief was determined using a WYKO NT 9800 Veeco Instrument Profilometer. The dimensions of the 2-D-scanned area are indicated on the xand y-axes of the 3-D color plot, and the surface relief is indicated in microns on the color-coded scale on the right-hand side of Fig. $1 \mathrm{~b}$.

Interference-contrast color micrographs are an alternate method that is ideally suited to revealing the details of the 3-D surface-relief features that result in the present decorative effect. As noted previously, decorative objects formed by utilizing "cuts" made along single-crystal surfaces with different orientations yield different decorative patterns. These patterns reflect the crystallographic symmetry of the material through their formation by the intersection of the phase-transformation-induced martensitic lathes with the (110), (111), and (100) austenitic crystal surfaces.

Figures $2 \mathrm{a}, \mathrm{b}$, and $\mathrm{c}$ are optical interference-contrast micrographs that provide clear illustrations of the differences between the decorative patterns formed on the (110), (111), and (100) surfaces of the $70 \mathrm{wt} \% \mathrm{Fe}-15 \mathrm{wt} \% \mathrm{Ni}-15 \% \mathrm{wt} \% \mathrm{Cr}$ alloy after cryogenic quenching. In addition to using "cuts" along principal crystallographic directions as in the case of Fig. 2, other randomly oriented "cuts" can be utilized, but regardless of the orientation of the cuts, every decorative pattern formed by cryogenic quenching of the single crystal alloy, as described here, is different. 

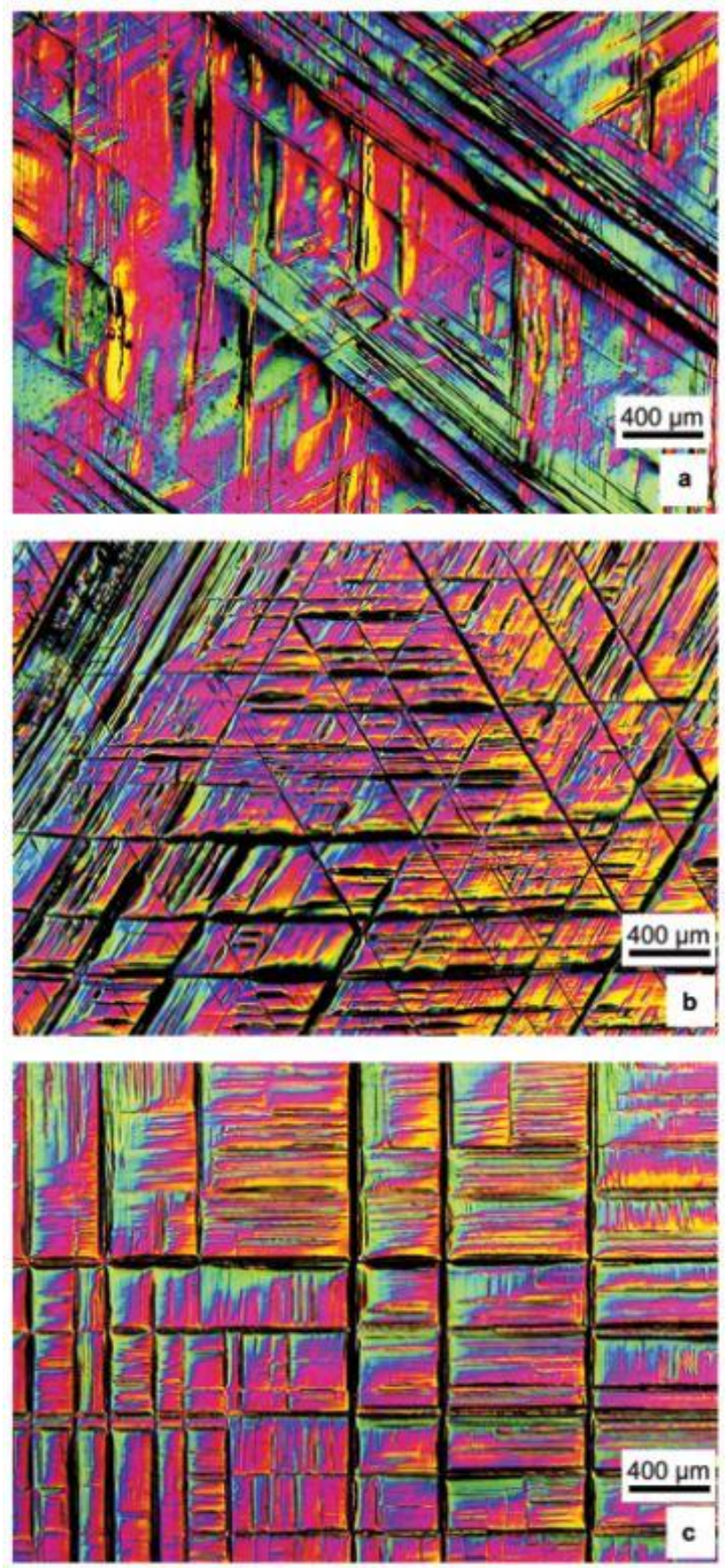

Fig. 2. Optical interference-contrast micrographs illustrating the symmetry of the decorative patterns formed on the surface of a transformed single-crystal $70 \mathrm{wt} \% \mathrm{Fe}-$ $15 \mathrm{wt} \% \mathrm{Ni}-15 \% \mathrm{wt} \% \mathrm{Cr}$ alloy are shown: (2a) for the (110) oriented surface. (2b) for the (111) surface, and (2c) for the (100) surface. 
As reflected in Fig. 1a, the transformed decorative material is heterogeneous in that it consists of two regions of differing crystalline phases (i.e., austenite and retained martensite) after cycling through the phase transition. However, unlike conventional polycrystalline commercial alloys, which are strengthened by the presence of numerous small grains and grain boundaries, this material is a single crystal (i.e., there is only one single grain) - so the normal hardening mechanisms that are operative in polycrystalline alloys are not active in this case. Additionally, no carbon was added to the pure ternary composition nor were any other additives (e.g., vanadium) present that could increase the hardness. Nevertheless, hardness variations are present in the different regions of the decorative material. These hardness variations were mapped out in 8 different regions of a (100)-oriented (transformed and then polished flat) sample using an automated nanoindentation system (iNano ${ }^{\circledR}$, Nanomechanics, Inc.). The indentation results for one of the mapped regions are shown in Fig. 3a along with an optical micrograph of the same region of the sample that is presented in Fig. 3b. The optical micrograph did not reveal large visual variations in contrast once the flat specimen was highly polished. This optical micrograph was taken before multiple indentations were made on the surface since the indentations inherent in the hardness mapping operation could further alter the appearance of the sample surface. This hardness map captures the topographic variations observed in the optical micrograph as well as the surface relief pattern that is present in the sample prior to lapping and polishing. These results show that the hardest regions are those that correspond to the originally higher profile (martensitic) surface features of the sample - although the magnitude of the variations in hardness is not extremely large as indicated by the hardness scale on the right-hand side of Fig. 3a. 


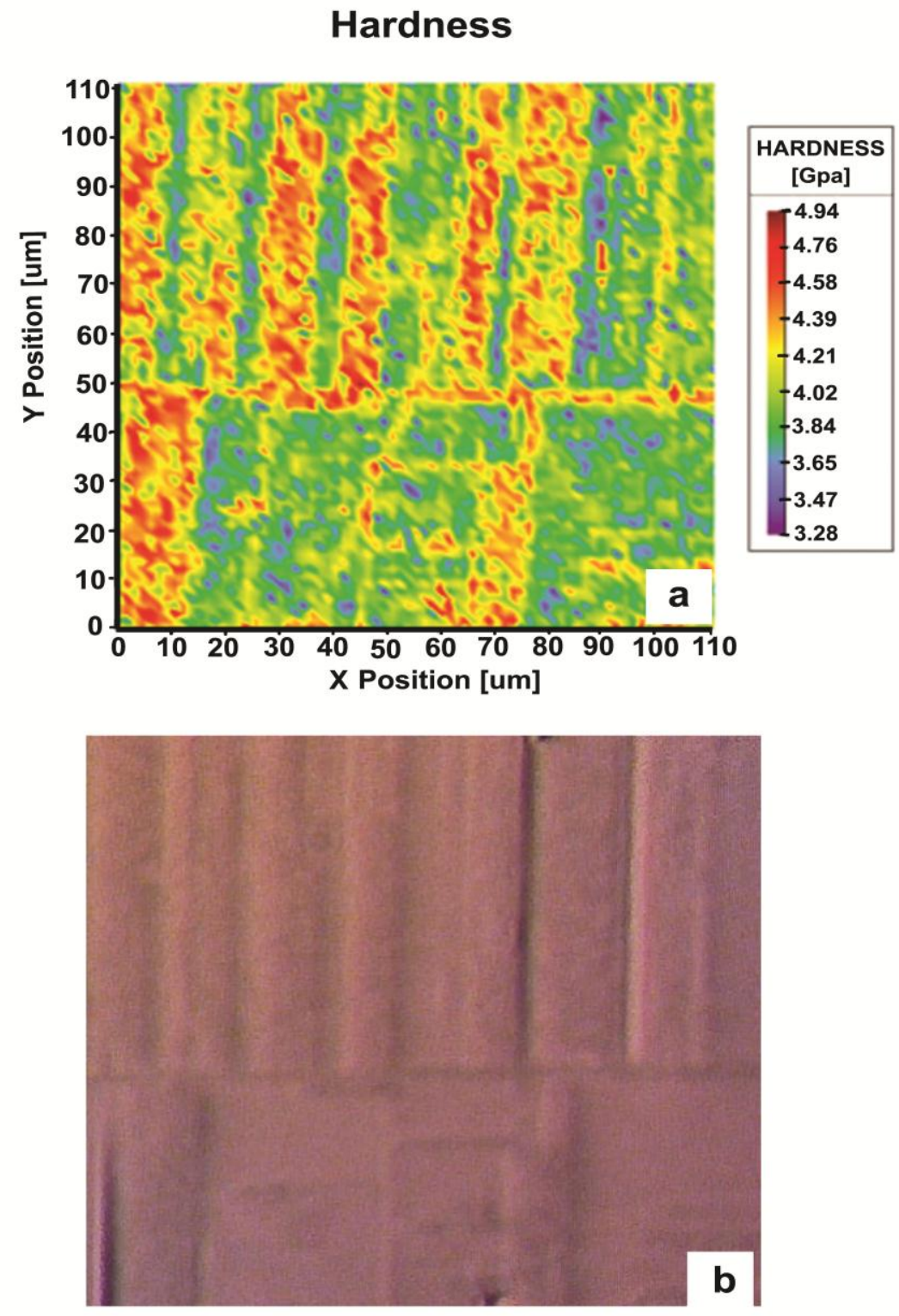

Fig. 3. (a) Hardness map of a $112.5 \times 112.5$ micron area of an as-transformed decorative steel sample. Each square indentation array consists of 5,625 indentations at an applied load of $2.5 \mathrm{mN}$. The indentations were spaced 1.5 microns apart; (b) An optical micrograph of the region mapped by nano-indentation is shown in Fig. 3a. 


\subsection{Summary and Conclusions}

The decorative steel whose properties and fabrication methods are described here has numerous potential practical applications including its use in custom made knives, kitchen and carving knives, pocket knives, etc., art objects, crafts, furniture, jewelry, automobile interiors, and interior design - i.e., in a wide range of decorative and utilitarian items. Examples of the use of this material in a custom made folding knife and in a Western style belt buckle are shown in Figs. 4a,b.

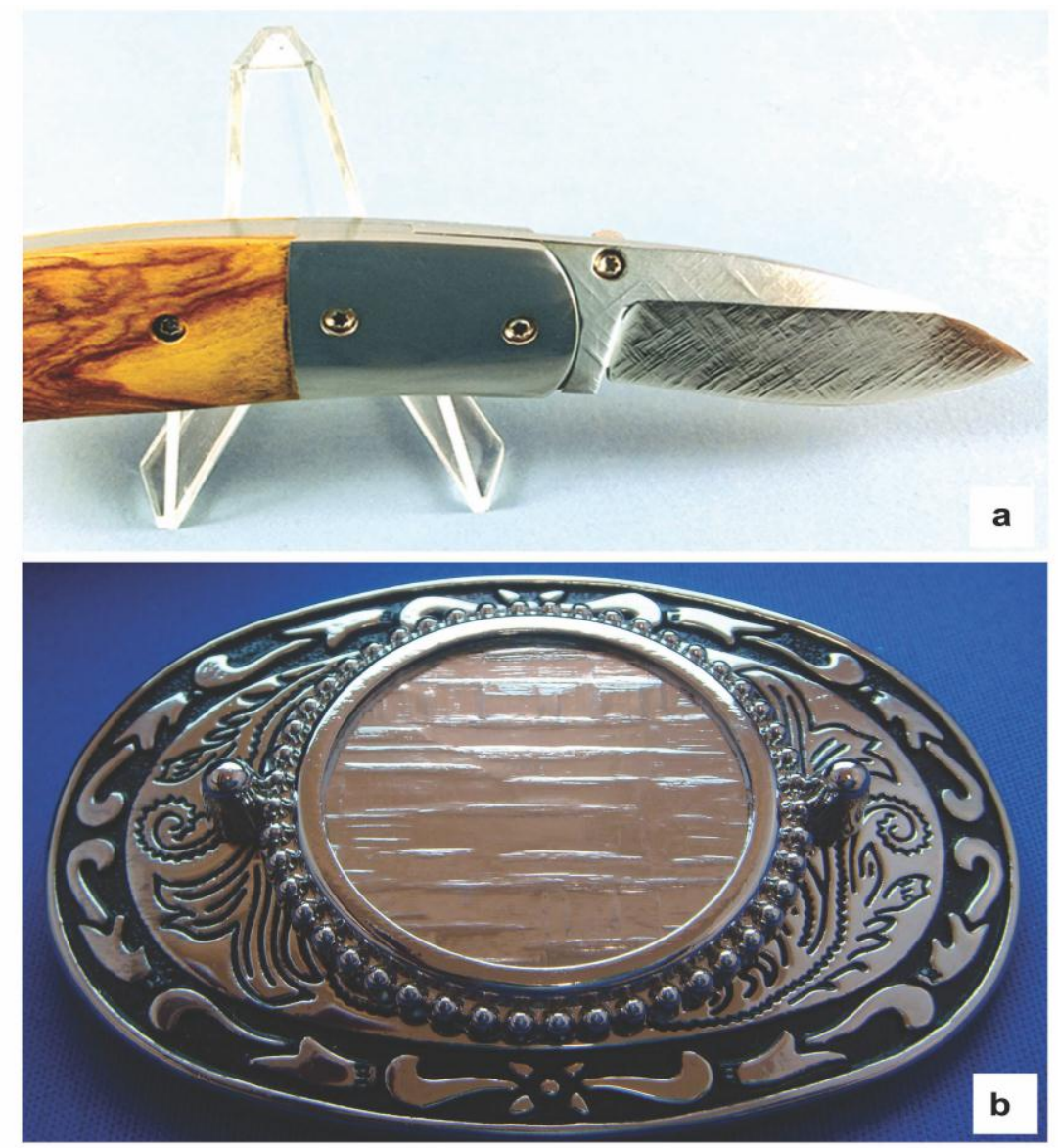

Fig. 4. (a). The ternary alloy decorative steel is used in the blade of a folding knife made by custom knife maker, Ronald Hewitt, of Adel, Georgia. The bolsters of the knife are titanium and the scales are olive wood, (b). A Western-style belt buckle that incorporates a central medallion of the decorative $70 \mathrm{wt} \% \mathrm{Fe}-15 \mathrm{wt} \% \mathrm{Ni}-15 \% \mathrm{wt} \% \mathrm{Cr}$ quenched alloy. 
The properties and fabrication methods are described here for a new steel whose decorative aspect arises from a three-dimensional surface pattern that results from cryogenically quenching polished austenitic alloy single crystals into the martensitic phase that is present below $190 \mathrm{~K}$. This very rapid and diffusionless martensitic phase transition is highly hysteretic, and when the alloy is returned to room temperature a residual amount of the martensitic phase is preserved. This remaining martensitic phase forms a distinct raised 3-D decorative "raised" pattern in the form of macroscopic extended laths on the surface of the alloy - as shown in Figs. 1a,b and 2,a,b,c. While the surface pattern of these martensitic laths reflects the symmetry of the orientation of the single-crystal austenitic alloy, the martensitic structure of the retained body-centered phase actually penetrates throughout the bulk of the material - and is not just present in the form of the three-dimensional pattern manifested on the surface. The austenitic alloy used here is non-magnetic - but the material becomes magnetic due to the presence of the retained martensitic phase that is present after cryo-quenching - so its presence can be readily and quickly established with a small magnet. The presence of the retained martensite after quenching has been further confirmed by X-ray diffraction methods. Unlike previous decorative steels, i.e., Damascus or pattern-welded steels, no forging operations are involved in producing the decorative aspect - the mechanism that produces the decorative pattern is entirely based on the metallurgical phase transition and physical properties of the ternary Fe-Ni-Cr alloy single crystal.

The optical mechanism responsible for the decorative pattern is based on reflections of light from the three-dimensional surface morphology formed by cryo- 
quenching the austenitic single crystal and, specifically, on the uneven relief of the surface as quantified in Fig. $1 \mathrm{~b}$ - i.e., this crenulated surface not only reflects the light but it provides a different and clearly changing visual aspect depending on the angle of viewing. This differs from both Damascus or pattern welded steels where the visual appearance is based on color differences between different portions of the Damascus microstructure or, in the pattern-welded case, the different components of the manufactured composite material. In fact, if the surface of the example shown in Fig. 1a is given a smooth, high polish, the decorative aspect almost entirely disappears, and the two different phases are barely discernable - even on close visual inspection. Martensitic materials and their characteristics have been extensively investigated (for example by Morris Cohen and G. B. Olson,[26] Larry Kaufman and Morris Cohen[27] , and numerous other investigators), and there is an enormous amount of literature available on this topic. It should be noted, however, that the features which produce the decorative aspect described here are arrested by grain boundaries, and therefore, are only intragranular in a conventional polycrystalline alloy material. Accordingly, the large-scale decorative surface patterns shown here in Fig. 1a in the case of a single crystal with a single grain and no grain boundaries would not be visible to the unaided eye in a conventional, polycrystalline alloy.

\section{Acknowledgements}

Research by L.A.B. and J.A.K. was supported by the U.S. Department of Energy, Office of Science, Basic Energy Sciences, Materials Sciences and Engineering Division. Research by N.V.L. was supported by the Theme Science Program at the Center for Nanophase Materials Sciences, sponsored by the Division of Scientific User Facilities, 
U.S. Department of Energy. Research by S. P. was supported by Nanomechanics, Inc., Oak Ridge Tennessee. The authors are indebted to Bryan Chakoumakos for his X-ray examination of the as-grown and transformed Fe-Ni-Cr single crystals and to Kurt

Johanns for his assistance with the nano-indentation data. The authors acknowledge with thanks the comments of Jeffrey Wadsworth on the manuscript and his suggestions for its improvement. 


\section{References}

[1] N. T. Belaiew, Damascene steel, J. Iron Steel Inst. (London) 97 (1918) 417-437.

[2] Sharada Srinivasan, S. Ranganathan, The significance of wootz steel to the history of materials science, National Institute of Advanced Studies and University of Exeter (2011) 1-4.

https:/humanities.exeter.ac.uk/media/universityofexeter/collegeofhumanities/arch aeology/documents/Telangana_Interim.pdf.

[3] S. Srinivasan, On Higher Carbon and Crucible Steels in Southern India: Further Insights from Mel-siruvalur; Kodumanal and Pattinam, Indian J. Hist. Sci., 42.4 (2007) 673-694.

http://www.insa.nic.in/writereaddata/UpLoadedFiles/IJHS/Vol42_4_8 SSrinivasa $\underline{\text { n.pdf. }}$

[4] John D. Verhoeven, "Genuine Damascus steel: a type of banded microstructure in hypereutectoid steels," Steel Res. 73 (2002) 356-365. Accession Number: WOS:000177673600006

[5] John D. Verhoeven, A. H. Pendray, Experiments to Reproduce the Pattern of Damascus Steel Blades, Mater. Charact. 29 (1992) 195-212 doi:10.1016/10445803(92)90115-X

[6] John D. Verhoeven, A. H. Pendray, W. E. Dauksch, The Key Role of Impurities in Ancient Damascus Steel Blades, JOM 50.9 (1988) 58-64 doi: 10.1007/s11837998-0419-y

[7] John D. Verhoeven, A. H. Pendray, E. D. Gibson, Wootz Damascus Steel Blades, Mater. Charact. 39 (1996) 9-2. doi:10.1016/S1044-5803(96)00019-8 
[8] John D. Verhoeven, The Mystery of Damascus Blades, Sci. Am. 284 (2001) 7479 doi:10.1038/scientificamerican0101-74

[9] Jeffrey Wadsworth, Oleg D. Sherby, On the Bulat—Damascus Steels Revisited, Prog. Matls Sci., 25 (1980) 35-68 doi:10.1016/0079-6425(80)90014-6

[10] Nikolai Kobasko, An Explanation of Possible Damascus Steel Manufacturing Based on Duration of Transient Nucleate Boiling Process and Prediction of the Future of Controlled Continuous Casting, Int. J. of Mech., 5.3 (2001) 182-190 https://www.researchgate.net/profile/Nikolai_Kobasko/publication/262153148_A n_explanation_of_possible_Damascus_steel_manufacturing_based_on_duration_ of_transient_nucleate_boiling_process/links/544aeedd0cf2d6347f41d814.pdf.

[11] Eric M. Taleff, Bruce L. Bramfitt, Chol K. Syn, Donald R. Lesuer, Jeffrey Wadsworth, Oleg D. Sherby, Processing, structure, and properties of a rolled, ultrahigh-carbon steel plate exhibiting a damask pattern, 461 (2001) 11-18 doi:10.1016/S1044-5803(00)00087-5.

[12] J. Verhoeven, H. H. Baker, D. T. Peterson, H. F. Clark, W. M. Yates, Damascus Steel, part III: The Wadsworth-Sherby mechanism, Mater. Charact., 24 (1990) 205-227 doi:10.1016/1044-5803(90)90052-L.

[13] Jeffrey Wadsworth, Oleg D. Sherby, Comments on "Damascus steel, part III: The Wadsworth-Sherby mechanism" by Verhoeven et al., Mater. Charact., 28 (1992) 165-172 doi:10.1016/1044-5803(92)90040-O.

[14] Jeffrey Wadsworth, Oleg D. Sherby, Response to Verhoeven comments on Damascus steel, Mater. Charact., 47 (2001) 163-165 doi:10.1016/S10445803(01)00184-X. 
[15] Oleg D. Sherby, Jeffrey Wadsworth, Damascus Steels, Sci. Amer., 252.5 (1985) 112-120 doi:10.1038/scientificamerican0285-112.

[16] Oleg D. Sherby, Jeffrey Wadsworth, Ancient blacksmiths, the Iron Age, Damascus steels, and modern metallurgy, J. Mater. Process. Technol., 117.3 (2001) 347-353 doi:10.1016/S0924-0136(01)00794-4.

[17] Jeffrey Wadsworth, Donald R Lesuer, Ancient and modern laminated composites — from the Great Pyramid of Gizeh to Y2K, 45 (2000) 289-313 doi:10.1016/S1044-5803(00)00077-2.

[18] Jeffrey Wadsworth, Ancient and Modern Steels and Laminated Composites Containing Steels, MRS Bull., 27 (2002) 980-987 http://dx.doi.org/10.1557/mrs2002.305.

[19] Oleg D. Sherby, Jeffrey Wadsworth, Ultrahigh carbon steels, Damascus steels, and superplasticity, preprint No. UCRL-JC-127180 Istanbul, Turkey: Lawrence Livermore National Library (1997) http://www.hefajstos.agh.edu.pl/files/[1997]\%20Ultrahigh\%20Carbon\%20Steels, \%20Damascus\%20Steels,\%20and\%20Superplasticity\%20-\%20O.\%20D.\%20Sher by\%20J.\%20Wadsworth.pdf.

[20] Jeffrey Wadsworth, Archeometallurgy related to swords, Mater. Charact., 99 (2015) 1-7. doi:10.1016/j.matchar.2014.10.019.

[21] Jan Czochralski, A new method for measuring the crystallization rate of the metals, Zeitschrift für Physikalische Chemie, 92 (1918) 219-221. 
[22] M. Rappaz, J. M. Vitek, S. A. David, L. A. Boatner, Microstructural formation in longitudinal bicrystal welds, Metall. Trans. A, 24.6 (1993) 1433-1446 DOI:10.1007/BF02668211.

[23] M. Rappaz, S. A. David, J. M. Vitek, L. A. Boatner, Analysis of solidification microstructures in Fe-Ni-Cr single-crystal welds, Metal. Trans. A, 21.6 (1990) 1767-1782 DOI: 10.1007/BF02672593.

[24] M. Rappaz, S. A. David, J. M. Vitek, L. A. Boatner, Development of microstructures in $\mathrm{Fe}-15 \mathrm{Ni}-15 \mathrm{Cr}$ single crystal electron beam welds, Metall. Trans. A, 20.6 (1989) 1125-1138 DOI: 10.1007/BF02650147.

[25] L. Boatner, J. Sipf, S. David, M. Rappaz, Metallographic Investigations of Solidification Microstructures and Melt-Pool Characteristics in Oriented Single Crystals of Stainless Steel, Microsc. Microanal., 12 Suppl. 02 (2006) 1604-1605 doi:10.1017/S1431927606066190.

[26] Morris Cohen, C. Marvin Wayman, Fundamentals of Martensitic transformations, Metallurgical Treatises, 445-468 (J.H. Tein, J. F. Elliot, eds.) Metall .Soc. AIME, Warrendale, PA (1981).

[27] Larry Kaufman, Morris Cohen, Thermodynamics and kinetics of martensitic transformations, Prog. Met. Phys., 7 (1958) 165-246 doi:10.1016/05028205(58)90005-4. 